\title{
The Assessment and Influence Factors Analysis of Development Level of Node Cities on the Maritime Silk Route
}

\author{
Lili \\ Qingdao University of Science and Technology \\ Qingdao 266061
}

Liukai

Qingdao Vocational and Technical of Hotel Management

\author{
Liyanlin \\ Qingdao University of Science and Technology \\ Qingdao 266061 \\ Wangpeng \\ Qingdao University of Science and Technology \\ Qingdao 266061
}

\begin{abstract}
On the basis of the requirements of assessing cities' development level, a new assessment system is set up, and an empirical study is conducted on the development level of 16 node cities by means of quantitative analysis and so on. The result indicates that there is a positive correlation between cities' development level and cities' size and cities' development level has an important connection with cities' environment and cities openness. In order to verify judgements above, 16 node cities are divided into 4 levels and features of cities in different levels are analyzed. Some factors influencing cities' development potentials are elaborated and some suggestions are put forward.
\end{abstract}

Keywords-“the Belt and Road"; Maritime Silk Route; Node Cities; Cities' Development Level; the Assessment of Development Level

Twenty-first century Maritime Silk Road which was proposed by the national chairman Xi Jinping after "the Silk Road Economic Zone" in 2013 is the new strategic concept in order to plan the domestic and international general situation as a whole. In March 2015, the National Development and Reform Commission, the Ministry of Foreign Affairs and the
Ministry of Commerce authorized by the State Council issued $<$ the promotion of the construction of the economic belt of the Silk Road and the vision and action of the twenty-first century Maritime Silk Road> and this will promote "the one belt and one road" strategy to a further strategic implementation stage ${ }^{[1]}$. Based on this background, this paper makes an evaluation on the development of the 16 node cities along the Silk Road of the sea and makes an analysis of the factors which influence the development of the city.

\section{ESTABLISHMENT OF EVALUATION SYSTEM FOR THE DEVELOPMENT DEGREE OF NODE CITY}

\section{A. Selection of evaluation factors.}

This paper chooses city scale, the opening of the city, the environment of the city and the development of the city as the basic evaluation factors of the urban development degree and establishes the evaluation index system of the city development degree.(see TABLE I)

TABLE I. THE EVALUATION INDEX SYSTEM OF THE CITY DEVELOPMENT DEGREE

\begin{tabular}{|c|c|c|}
\hline First-level index & 2-level index & 3-level index \\
\hline \multirow{6}{*}{ A.city scale } & \multirow{2}{*}{ A1 construction scale } & A11 urban built-up area(Square kilometers) \\
\hline & & A12 total urban resident population(Million people ) \\
\hline & \multirow{4}{*}{ A2 economy scale } & A21 the whole city's GDPB(Billion yuan) \\
\hline & & A22 per capita GDP(Million yuan) \\
\hline & & A23 total retail sales of social goods(Billion yuan) \\
\hline & & A24 total investment in fixed assets(Billion yuan) \\
\hline \multirow{5}{*}{ B.city open } & \multirow{2}{*}{ B1port resources } & B11 total port throughput(Million tons) \\
\hline & & B12 container handling capacity(Million TEUs) \\
\hline & \multirow{3}{*}{ B2foreign trade } & B21 city's total exports(Billion dollar) \\
\hline & & B22 city's total imports(Billion dollar) \\
\hline & & B23 actual utilization of foreign capital scale(Million dollar) \\
\hline \multirow{2}{*}{ C.city environment } & \multirow{2}{*}{ C1social environment } & C11 number of ordinary colleges and universities(Pcs) \\
\hline & & C12 library collection of public libraries per million people(Pcs \\
\hline
\end{tabular}




\begin{tabular}{|c|c|c|}
\hline \multicolumn{3}{|c|}{ TABLE I, cont. } \\
\hline & & C13 hospital bed number(Pcs) \\
\hline & & C14 numbers of doctors per ten thousand people(Person) \\
\hline & & $\begin{array}{l}\text { C15 numbers of internet users per ten thousand people(Door/ten } \\
\text { thousand) }\end{array}$ \\
\hline & & C16 numbers of employees in the financial sector(ten thousand) \\
\hline & \multirow{4}{*}{ C2living condition } & C21 per capita urban road area(Square meters/person) \\
\hline & & $\mathrm{C} 22$ residential electricity consumption(Ten thousand $\mathrm{KWH}$ ) \\
\hline & & $\mathrm{C} 23$ residential water consumption(Ten thousand tons) \\
\hline & & C24 per capita living area(Square meters/person) \\
\hline & \multirow{6}{*}{ C3natural environment } & C31 industrial solid waste comprehensive utilization(\%) \\
\hline & & C32 discharge standard rate of industrial waste water $(\%)$ \\
\hline & & C33 domestic waste harmless treatment rate $(\%)$ \\
\hline & & C34 built-up area green coverage rate $(\%)$ \\
\hline & & C35 per capita green area of the city(Square meters/person) \\
\hline & & C36 good air quality rate $(\%)$ \\
\hline \multirow{11}{*}{ D.city development } & \multirow{4}{*}{ D1 industrial structure } & D11secondary industry employees proportion(\%) \\
\hline & & D12 second industrial output value accounted for GDP(\%) \\
\hline & & D13 employees proportion of third industry $(\%)$ \\
\hline & & D14 third industrial output value accounted for GDP(\%) \\
\hline & \multirow{3}{*}{ D2innovation ability } & D21 the proportion of science and technology activity funds in sales $(\%)$ \\
\hline & & D22 invention patent authorization amount(Pcs) \\
\hline & & $\begin{array}{l}\text { D23 the number of scientific and technological personnel of } 10000 \text { staff } \\
\text { and workers(Pcs) }\end{array}$ \\
\hline & \multirow{4}{*}{$\begin{array}{l}\text { D3government } \\
\text { administration }\end{array}$} & D31 fiscal revenue accounted for GDP(\%) \\
\hline & & $\begin{array}{l}\text { D32 the proportion of the government employees accounted for the total } \\
\text { employment population (\%) }\end{array}$ \\
\hline & & D33 total investment in environment pollution(Million yuan) \\
\hline & & $\begin{array}{l}\text { D34 science and education culture business expenses accounting for the } \\
\text { proportion of GDP }(\%)\end{array}$ \\
\hline
\end{tabular}

\section{B. Extraction and analysis of main components}

On the basis of the above indicators, the paper obtains the data of principal component characteristic value, contribution rate and.(see TABLE II)

TABLE II. THE VARIANCE CONTRIBUTION RATE

\begin{tabular}{|c|c|c|c|c|}
\hline Component & Characteristic value & Contribution rate (\%) & $\begin{array}{c}\text { Cumulative contribution } \\
\text { rate(\%) }\end{array}$ & Weight \\
\hline F1 & 15.840 & 41.685 & 41.685 & 0.447 \\
\hline F2 & 6.058 & 15.941 & 57.626 & 0.171 \\
\hline F3 & 3.792 & 9.979 & 67.605 & 0.107 \\
\hline F4 & 2.998 & 7.889 & 75.494 & 0.065 \\
\hline F5 & 2.287 & 6.019 & 81.513 & 0.054 \\
\hline F6 & 1.920 & 5.054 & 86.567 & 0.04 \\
\hline F7 & 1.427 & 3.756 & 90.323 & 0.032 \\
\hline F8 & 1.146 & 3.016 & 93.339 & 0.065 \\
\hline
\end{tabular}

From TABLE II, the cumulative contribution rate of the aforementioned 8 main components has reached $93.339 \%$, According to this; we can explain $93.339 \%$ information of the original 38 variables. In view of this, this paper extracts 8 main components as analysis object, and calculates their component transformation matrix. (see TABLE III). 
TABLE III. COMPONENT TRANSFORMATIONG MATRIX

\begin{tabular}{|c|c|c|c|c|c|c|c|c|}
\hline & F1 & $F 2$ & F3 & F4 & F5 & F6 & F7 & F8 \\
\hline A11 urban built-up area(Square kilometer) & .845 & 338 & 057 & 304 & -150 & 028 & 023 & -.134 \\
\hline A12 total urban resident population(Ten thousand people) & .871 & 403 & -126 & -171 & .142 & 032 & -.071 & -.001 \\
\hline A21 the whole city's GDP(Billion yuan) & .905 & 389 & -011 & 114 & -.056 & -.036 & 001 & 000 \\
\hline A22 per capita GDP(Million yuan) & .576 & 249 & -.050 & 639 & 121 & -.239 & 226 & 115 \\
\hline A23 total retail sales of social goods(Billion yuan) & .908 & 336 & 013 & 022 & -176 & .090 & 052 & -.046 \\
\hline B11 total port throughput(Million tons) & .616 & 517 & -066 & -.060 & -.004 & -.351 & 390 & 107 \\
\hline B12 container handling capacity(Million TEUs) & .881 & 259 & 004 & 145 & 164 & -.076 & 076 & 063 \\
\hline B21 city's total exports(Billion dollars) & .888 & -120 & .027 & 297 & 218 & 069 & -.090 & 143 \\
\hline B22 city's total imports(Billion dollars) & .948 & 053 & 048 & 075 & 223 & 057 & -.077 & 081 \\
\hline B23 actual utilization of foreign capital scale(Million dollars) & .591 & 680 & .004 & .024 & 239 & -.179 & -.090 & -.160 \\
\hline $\begin{array}{l}\text { C12 library collection of public libraries per million } \\
\text { people(Book) }\end{array}$ & .781 & -.217 & 008 & 425 & 293 & 042 & .060 & 049 \\
\hline C13 hospital bed number(Number of bed) & .822 & 437 & 002 & -.187 & -193 & -.169 & 025 & -.057 \\
\hline C14 numbers of doctors per ten thousand people(People) & -.043 & 161 & 483 & 603 & .067 & -.507 & 265 & 059 \\
\hline $\begin{array}{l}\text { C15 numbers of internet users per ten thousand } \\
\text { people(Households / million) }\end{array}$ & .154 & 685 & -.023 & 561 & -.008 & 241 & 159 & 121 \\
\hline $\begin{array}{l}\text { C16 numbers of employees in the financial sector(Million } \\
\text { people) }\end{array}$ & .897 & 212 & 104 & -.251 & 131 & -.088 & 033 & 009 \\
\hline C21 per capita urban road area(Square meter / person) & .251 & -.069 & .350 & 801 & 080 & 007 & .051 & 291 \\
\hline $\begin{array}{l}\text { C22 residential electricity consumption(Million kilowatt } \\
\text { hours) }\end{array}$ & .907 & 160 & 126 & 137 & -114 & 117 & 056 & -.139 \\
\hline C23 residential water consumption(Million tons) & .924 & 049 & 193 & 202 & -.096 & 080 & 071 & -116 \\
\hline C24 per capita living area(Square meter / person) $)^{a}$ & .219 & -.138 & 694 & 097 & 550 & .045 & .001 & .317 \\
\hline C31 industrial solid waste comprehensive utilization(\%) & .026 & -.144 & 221 & -.040 & 074 & 931 & 045 & 061 \\
\hline C33 domestic waste harmless treatment rate $(\%)$ & -.052 & -.001 & 096 & 117 & 027 & 061 & .030 & 951 \\
\hline C34 built-up area green coverage rate $(\%)$ & .035 & 029 & .239 & 675 & .267 & -.010 & -.338 & -.338 \\
\hline C35 per capita green area of the city(Square meter / person) & .102 & 031 & 295 & 068 & -138 & 010 & 902 & -.088 \\
\hline C36 good air quality rate(\%) & -.398 & -.875 & .007 & .008 & 053 & 021 & .073 & -.064 \\
\hline D11 secondary industry employees proportion (\%) & .081 & -.004 & -920 & 298 & .016 & -.025 & .080 & -.052 \\
\hline D12 second industrial output value accounted for GDP(\%) & -.036 & 106 & -.971 & 044 & 008 & -.135 & -.007 & -.100 \\
\hline D13 employees proportion of third industry(\%) & -.030 & 042 & 890 & -.314 & 053 & 019 & 149 & 044 \\
\hline D14 third industrial output value accounted for GDP(\%) & .293 & -.004 & 895 & 182 & 039 & 134 & 030 & -.006 \\
\hline $\begin{array}{l}\text { D21 the proportion of science and technology activity funds } \\
\text { in sales }(\%)\end{array}$ & $\mid .346$ & 150 & -.393 & 492 & 046 & -.126 & -.082 & 349 \\
\hline D22 invention patent authorization amount(Piece) & .942 & -.001 & 052 & 213 & 148 & 078 & -.055 & 103 \\
\hline $\begin{array}{l}\text { D23 the number of scientific and technological personnel of } \\
10000 \text { staff and workers(People / million) }\end{array}$ & .391 & 398 & 443 & .069 & -612 & .027 & -.051 & 061 \\
\hline D31 fiscal revenue accounted for GDP (\%) & .358 & 229 & 364 & -.057 & 717 & 134 & -.043 & 168 \\
\hline $\begin{array}{l}\text { D32 the proportion of the government employees accounted } \\
\text { for the total employment population }(\%)\end{array}$ & -.374 & 595 & 350 & .282 & 074 & 243 & -.313 & 065 \\
\hline D33 total investment in environment pollution(Billion yuan) & 639 & 694 & -.185 & 063 & 055 & -.159 & -.109 & 052 \\
\hline $\begin{array}{l}\text { D34 science and education culture business expenses } \\
\text { accounting for the proportion of GDP }(\%)\end{array}$ & .085 & 188 & 243 & -.501 & 560 & 517 & -.118 & 071 \\
\hline
\end{tabular}

${ }^{\mathrm{a}}$ By the limit of statistical data, the per capita living area index is replaced by the index of per capita living space.

Calculation results show that:(1)F1 is a factor of the development of city economy, the characteristic value is
15.84 ,variance contribution rate is $41.685 \%$,the principal component weight is $44.7 \%$.(2)F2 is a factor of the government 
service status, the characteristic value is 6.058, variance contribution rate is $15.941 \%$, the principal component weight is $17.1 \%$. (3)F3 is a factor of the economy structure, the characteristic value is 3.792 , variance contribution rate is $9.979 \%$, and the principal component weight is $10.7 \%$. (4)F4 is a factor of the urban resident life. The characteristic value is 2.998 , variance contribution rate is $7.889 \%$, and the principal component weight is $8.4 \%$. (5)F5 is a factor of the market in the national income distribution. The characteristic value is 2.287; variance contribution rate is $6.019 \%$. the principal component weight is 6.5.\%.(6)F6 is a factor of the development of city economy, the characteristic value is 1,920 ,variance contribution rate is $5.054 \%$, the principal component weight is $5.4 \%$.(7)F7 is a factor of the urban ecological impact, the characteristic value is 1.427 .variance contribution rate is $3.756 \%$, the principal component weight is $4 \%$. (8)F8 is a factor of the city environment, the characteristic value is 1.146 , variance contribution rate is $3.016 \%$, the principal component weight is $3.2 \%$.

\section{DEVELOPMENT SCORE AND RANKING}

A. Principal component comprehensive score and classification feature

By using the following formula, we can obtain the comprehensive score and ranking of the main components in the city. (See table 5 and 6)

$$
\begin{aligned}
& F a=c_{a} \div \sum c_{a} \\
& S a=\sum S a j \times f j
\end{aligned}
$$

$f a$ is the weight coefficient of each principal component.

$\mathrm{Ca}$ stands for principal component contribution rate.

Saj stands for the score of city $\mathrm{j}$ in the principal component.

$S j$ stands for the comprehensive score of city $\mathrm{j}$.

\begin{tabular}{|c|c|c|c|c|c|c|c|c|c|}
\hline & $\mathrm{F} 1$ & $\mathrm{~F} 2$ & F3 & F4 & F5 & F6 & F7 & F8 & $\begin{array}{l}\text { comprehensive } \\
\text { score }\end{array}$ \\
\hline Tianjin & -0.10 & 7.54 & -0.57 & 0.13 & 0.58 & 1.57 & -0.84 & 0.04 & 1.28 \\
\hline Dalian & -1.05 & 0.91 & -0.04 & 0.79 & 1.24 & -3.46 & -0.27 & -1.88 & -0.43 \\
\hline Yantai & -1.34 & -0.44 & -1.03 & -0.40 & -0.74 & -2.46 & -0.88 & 1.09 & -1 \\
\hline Qingdao & -1.53 & 2.89 & -0.59 & 2.10 & -0.33 & 0.33 & 0.11 & 0.46 & -0.06 \\
\hline Zhoushan & -3.42 & -0.98 & -0.02 & 0.15 & 1.09 & 0.48 & 3.39 & 0.65 & -1.43 \\
\hline Ningbo & -0.19 & 0.34 & -1.69 & -0.74 & 0.83 & -1.48 & 0.72 & 1.09 & -0.23 \\
\hline Fouzhou & -0.82 & -0.54 & -0.59 & 0.34 & -1.21 & -0.09 & -0.93 & 0.47 & -0.6 \\
\hline Quanzhou & -0.96 & -1.62 & -3.61 & -0.52 & -0.77 & 0.62 & -0.26 & 0.02 & -1.16 \\
\hline Xiamen & -1.28 & -1.11 & -0.48 & 1.12 & 1.18 & 0.79 & 0.62 & -0.04 & -0.58 \\
\hline Guangzhou & 3.73 & 0.95 & 2.11 & 1.21 & -3.38 & -0.07 & 1.76 & -0.98 & 1.97 \\
\hline Shenzhen & 6.57 & -3.37 & -0.43 & 3.75 & 1.12 & 1.06 & -1.13 & 0.59 & 2.74 \\
\hline Zhenjiang & -1.83 & -1.19 & -0.35 & -2.84 & -2.20 & 0.85 & -0.57 & 0.87 & -1.39 \\
\hline Haikou & -3.40 & -1.31 & 4.06 & 0.75 & -1.23 & -0.14 & -1.02 & -0.04 & -1.374 \\
\hline Sanya & -3.86 & -0.67 & 3.73 & -1.41 & 2.49 & 0.73 & -0.64 & 0.46 & -1.369 \\
\hline
\end{tabular}

TABLE IV. EACH PRINCIPAL COMPONENT SCORE AND COMPREHENSIVE SCORE OF NODE CITY

\begin{tabular}{|c|c|c|c|c|c|c|c|c|c|}
\hline & $\mathrm{F} 1$ & $\mathrm{~F} 2$ & F3 & F4 & F5 & F6 & F7 & F8 & Ranking \\
\hline Tianjin & 4 & 1 & 10 & 9 & 8 & 1 & 12 & 10 & 4 \\
\hline Dalian & 8 & 4 & 6 & 5 & 2 & 16 & 8 & 15 & 7 \\
\hline Yantai & 10 & 7 & 13 & 10 & 11 & 15 & 13 & 2 & 10 \\
\hline Qingdao & 11 & 2 & 11 & 2 & 10 & 9 & 6 & 7 & 5 \\
\hline Shanghai & 1 & 5 & 4 & 16 & 6 & 13 & 5 & 9 & 1 \\
\hline Zhoushan & 15 & 10 & 5 & 8 & 5 & 8 & 1 & 4 & 16 \\
\hline Ningbo & 5 & 6 & 15 & 12 & 7 & 14 & 3 & 1 & 6 \\
\hline Fouzhou & 6 & 8 & 12 & 7 & 13 & 11 & 14 & 6 & 9 \\
\hline Quanzhou & 7 & 14 & 16 & 11 & 12 & 7 & 7 & 11 & 11 \\
\hline
\end{tabular}

TABLE V. RANKING OF THE COMPREHENSIVE SCORE OF EACH NODE CITY 


\begin{tabular}{|l|l|l|l|l|l|l|l|l|l|l|}
\hline \multicolumn{10}{|c|}{ TABLE V, cont. } \\
\hline Xiamen & 9 & 11 & 9 & 4 & 3 & 5 & 4 & 12 & 8 \\
\hline Shantou & 12 & 15 & 14 & 13 & 9 & 2 & 9 & 16 & 15 \\
\hline Guangzhou & 3 & 3 & 3 & 3 & 16 & 10 & 2 & 14 & 3 \\
\hline Shenzhen & 2 & 16 & 8 & 1 & 4 & 3 & 16 & 5 & 2 \\
\hline Zhenjiang & 13 & 12 & 7 & 15 & 15 & 4 & 10 & 3 & 14 \\
\hline Haikou & 14 & 13 & 1 & 6 & 14 & 12 & 15 & 13 & 13 \\
\hline Sanya & 16 & 9 & 2 & 14 & 1 & 6 & 11 & 8 & 12 \\
\hline
\end{tabular}

From the table IV and table V, we can see that the cities scored as positive: Shanghai(5.04), Shenzhen(2.74), Guangzhou(1.97)and Tianjin(1.28). The cities scored negative: Qingdao(-0.06), Ningbo(-0.23), Dalian(-0.43), Xiamen(-0.58),
Fuzhou(-0.6), Yantai(-1), Quanzhou(-1.16), Sanya(-1.369), Haikou(-1.374), Zhanjiang(-1.39), Shantou(-1.41), Zhoushan(1.43). According to the score of 16 nodes in the city, it can be divided into 4 different development types (See TABLE VI).

TABLE VI. URBAN DEVELOPMENT DEGREE CLASSIFICATION

\begin{tabular}{|l|c|c|c|}
\hline \multicolumn{1}{|c|}{ Group Standard } & City Name & Type of Development & Amount \\
\hline the first class(>3) & Shanghai & $\begin{array}{c}\text { the highest degree of } \\
\text { development }\end{array}$ & 1 \\
\hline the second class(0 3) & Shenzhen, Guangzhou, Tianjin & $\begin{array}{c}\text { the higher degree } \\
\text { development }\end{array}$ & 3 \\
\hline the third class(-1 0) & Qingdao, Ningbo, Dalian, Xiamen, Fuzhou & general development & 5 \\
\hline the fourth class $(<-1)$ & $\begin{array}{c}\text { Yanta, Quanzhou, Sanya, Haikou, } \\
\text { Zhanjiang, Shantou, Zhoushan }\end{array}$ & $\begin{array}{c}\text { the more weak } \\
\text { development degree }\end{array}$ \\
\hline
\end{tabular}

(1)The highest degree of development (Shanghai). Features: large size of its economy, large population, obvious advantage of resource aggregation, powerful finance strength. But Shanghai have high pressure in environmental management, high cost of resident life, per capita GDP indicators is behind Shenzhen and Guangzhou.

(2)The higher degree development (Shenzhen, Guangzhou, Tianjin). Shenzhen city outstanding innovation output, but has little space; Guangzhou has advantages in higher education, health care, city space is large, but the total amount of import and export, invention patents behind Shanghai, Shenzhen. The Tianjin economy is large, but the per capita disposable income is low, the environmental pressure.

(3)General development degree (Qingdao, Ningbo, Dalian, Shamen, Fuzhou). The environment condition in Xiamen scores higher; Fuzhou's provincial administrative center status play a certain role in promoting the development of the city. Qingdao, Ningbo, Dalian, Xiamen is planned single city, our country has certain support to their development, but they are not the regional administrative center.

(4)The more weak development degree (Yantai, Quanzhou, Sanya, Haikou, Zhenjiang, Shantou, Zhoushan). The common features are: small population, good environmental condition, but less output, resource aggregation effect is not significant.

\section{B. Development degree of influencing factors and performance}

First, for the validation of the relationship between the city scale and the node cities' development level, to compare the seven largest GDP node city the size of the population, GDP and fixed asset investment scale. The results show that: city scale is positively related to urban development cities' development level, the big cities have the obviously "Matthew effect" in gathering resources.

Second, to verify the urban open relationship with the node degree of urban development, to reflect the node related indicators of urban open level resolution. The results showed that 16 nodes almost include China's most important seaport city. With the corresponding port conditions, these urban openness indicator performances are very excellent.

Third, in order to reflect the city environmental impact on city development degree of the node, select the number of doctors million people have, the number of million people in the Internet, the per capita living area per capita, City Road area, the per capita green area 5 indexes were calculated in their digits in 16 nodes in the city, and compares each node in the city the corresponding index and the median deviation information can be obtained and the indexes of the median. Results show: (1) The median number of doctors per million people is 24.52, the index is the highest level in Haikou, equivalent to the median of $127.57 \%$; the lowest is Zhanjiang, equivalent to the median $63.50 \%$. (2) In the number of bits per million people in the Internet the number is 2784.50 the index, the highest level in Qingdao, equivalent to the median of $237.58 \%$; the lowest is Zhanjiang, equivalent to the median $38.82 \%$. (3) Median per capita City Road area is 14.74 square meters, the index level is the highest in Shenzhen, equivalent to the median 237.58\%; the lowest is Shantou, equivalent to the median $31.48 \%$. (4) Median per capita living area is 29.50 square meters, the index level is the highest in Quanzhou, 
equivalent to the median of $155.93 \%$; the lowest is Shantou, equivalent to the median $59.53 \%$. (5) In the number of bits per capita green area is 19.73 square meters, the index level Zhoushan is the highest, the lowest is equivalent to the median of $591.49 \%$; Shenzhen, equivalent to the median $45.82 \%$.

Fourth, to reflect the relationship between city development and city development degree. The vitality of innovation input and output is analyzed. The results show that the reciprocal causation relationship between the two. Taking Shenzhen as an example, R\&D internal funds spending in 2014 accounted for $3.68 \%$ of GDP, the invention patents amounted to 12032 (ranked first), and innovation driving has become an important driving force to promote the development of Shenzhen.

\section{NODE CITY DEVELOPMENT STRATEGIES AND MEASURES}

\section{A. To create open to the public good environment}

"Twenty-first Century Maritime Silk Road" of strategy implementation process is long and complex. We must uphold equality, mutual benefit, adhere to the principle of long-term efforts, and actively explore cooperation with other organizations can achieve effective convergence, and can meet the international cooperation a new mechanism of reform of the global governance system ${ }^{[1]}$. To this end, it is necessary to do a good job of 3 key workers: (1) the breakthrough geographical and cultural constraints, building equality, openness, mutual benefit and new multilateral friendly relations conducive to common development, the formation of new opening mechanism; (2) the balance of investment relations between developed and developing countries and trade balance, "bringing in" and "go out" interests, develop new trade and investment; (3) out of the economic interests of the mode of thinking, concern each other's core interests, difficult to understand each other, take care of each other's needs, to give each other time to loose, inclusive attitude, open minded, and drive along national and regional political trust, economic cooperation And humanity tolerance ${ }^{[2]}$.

\section{B. Create new connectivity}

The key task of the" twenty-first Century Maritime Silk Road" is the construction of a new mechanism of interconnection. The target is to form an efficient interconnection network infrastructure, economy complementary transformation for the development of thrust, to create a regional supply chain, a new industrial chain, value chain, to achieve regional integration foundation ${ }^{[3]}$.To this end, it is necessary to do a good job in 4 key work: (1)Actively promote the maritime Silk Road in the eastern part of the city and the cooperation between Japan and South Korea and the main port of cooperation in the field of foreign trade; (2) The scientific planning of Shanghai port, Ningbo Zhoushan port Shanghai port cooperation system, support the formation of high-end port service industry developed international port; support for the Ningbo - Zhoushan port to become large transit, collection and distribution hub, and build a world-class shipping center and Shanghai port complement each other; (3) The integration of Meizhou Bay North Port Group, strategic thrust lifting Fujian global support for the construction of the maritime Silk Road; (4) To promote the integration of Hong
Kong and Macao, to create a world-class new economic region, examples of cooperation create a flourishing ${ }^{[4]}$.

\section{Expand the international cultural exchange channels}

Twenty-first Century "maritime Silk Road" covers the civilization is numerous, but the lack of cohesion between each other. To reduce this kind of cooperation between must create more obstacles, and the "maritime Silk Road" along national and regional cultural exchanges, promotes wider nongovernmental exchanges and communication between civilization and tolerance as a basic strategic goal. Therefore, to do 3 priorities: (1) promote different development level, different cultural traditions, different resource endowments, national equality and cooperation with different social systems, sharing the fruits of development; (2) to start sharing the personnel training system, build cultural exchange channel for the pilot program of cooperation, and strive to through a variety of education and culture different cultural exchange programs, promote mutual understanding and spiritual communication, let the world understand each node so that each node city, the city has more to the world of the channel; (3) the Australia FTA, since China and South Korea international cooperation agreement signing trade areas of opportunity, facing a breakthrough in international cooperation in the bottle Neck constraints, as the maritime Silk Road along the various nodes of the city to create a new situation in depth development of international economic cooperation and cultural exchange ${ }^{[5]}$.

\section{Innovation is mutually beneficial and win-win cooperation mode}

"The twenty-first Century Maritime Silk Road strategy" to meet the requirements of mutual benefit and win-win principle, symbiosis, change the output of cheap consumer goods and to obtain energy and mineral resources to the developing countries in the traditional way of cooperation, mutual benefit and win-win cooperation model innovation, constantly enrich the connotation and the way of international trade and economic cooperation. Therefore, to do 3 priorities: (1) improve our country simply rely on cheap goods to promote economic cooperation in the output image, through effective capital output, improve the international status and international influence, at the same time, also brought new opportunities for cooperation between countries; (2) to strengthen the enterprise investment cooperation subject status, guide enterprises especially private the enterprise to break the shackles of the traditional business model, to fully participate in the international competition, constantly enhance the ability among the international market; (3) strengthen cross-cultural communication, intensify the cultivation of talents, forwardlooking and intellectual culture foundation for the guarantee for the node city international cooperation.

\section{E. Cultivate a new growth pole of regional economy}

Relying on the" twenty-first Century Maritime Silk Road" is the trade and investment cooperation, strengthen cooperation in the construction of demonstration area and the test area, the new city group and the economic development drives the new growth pole of regional economy construction has important significance of. Therefore, to do 3 priorities: (1) To actively 
promote the country has set up a free trade experimentation area, national economic area and deep docking in twenty-first Century "maritime Silk Road", to further enhance the city development degree of each node and the "maritime Silk Road" service ability; (2) According to the "sea silk the road along national and regional cooperation and economic reflect the demands of different shape, promote the gradient of technical cooperation, to promote industrial advantages, support industrial chain transfer, the construction of win-win system of international division of labor; (3)According to the new form, new mechanisms to promote the development of regional economic integration.

\section{F. Strengthen the nodes between cities and urban development coordination between subsystems}

In the implementation process of the maritime Silk Road in twenty-first Century, the coordination between the different nodes of the urban and the internal subsystem has an important influence on the strategic objectives.

Therefore, to do 3 priorities: (1) according to the degree of correlation with the elements of city development, find out the limiting factors to hinder the regional development, promote regional economic coordinated development towards the direction of sustainable development ${ }^{[6]} ;(2)$ according to the characteristics and development orientation of each city, between the push node city to establish a coordination mechanism. In order to enhance cooperation and coordination between the various nodes of the city; (3) the innovation of twenty-first Century "maritime Silk Road" at home and abroad to promote ways and channels to strengthen the elements of security system, the formation of internal and external cooperation, orderly operation, the development situation of parties coordination, "twenty-first Century maritime silk road construction task really Fall to real point, and long-term adherence to achieve results.

\section{SUMMARY}

This article take development status of the important Node Cities on the 21st Century Maritime Silk Route as the research target, analyzing the influence factors of the city development degree, setting up the evaluation index system of the city development degree, using SPSS software to calculate the 16 node cities' comprehensive rankings. On the basis of this to classify the city development degree, the result indicates that the cities' development degree can be divided into four grades. Among them, a positive correlation between cities' size and cities' development level, cities' development level has an important connection with cities' openness; innovation capacity and environmental quality have the same direction to promote the role to the city development degree. At last, this paper put forward the suggestions from the environment of opening to the outside, interconnection mechanism, cultural exchanges, cooperation mode, regional economic development, city coordination degree.

\section{REFERENCES}

[1] National Development and Reform Commission, The ministry of foreign affairs, The ministry of commerce .Promote then construction of the Silk Road Economic Zone and the twenty-first Century Maritime Silk Road vision and action[EB/OL].http://media.china.com.cn/2015-03-28.(In Chinese)

[2] Shenhoujie, Xiaojincheng. International regional economic cooperation in the new situation and our country "The Belt and Road strategic cooperation [J]. Macroeconomic Research,2014(11):30-38.(In Chinese)

[3] Houlimin.Maritime Silk Road strategy in twenty-first Century, the background, positioning and Implementation Path[J].Journal of huaihai institute of technology (Humanities and social science edition) .2015(6):14-16.(In Chinese)

[4] Xujianping. Qingdao to build the "twenty-first Century Maritime Silk Road" hub city research[J].Journal of Qingdao university of science and technology (social science edition), 2014(6):6-8.(In Chinese)

[5] Huangmaoxing, Jiaxuekai. The strategic characteristics and development vision of the spatial scope of the maritime Silk Road in twenty-first Century[J].The southeast academic ,2015(4):71-79.(In Chinese)

[6] Hemaochun, Zhangjibing. Analysis of the national strategy of the new Silk Road Economic Zone -- China's historical opportunity, potential challenges and C.(In Chinese)

[7] Xuqian,Zhongchenli. Study on the regional economic coordination of the Silk Road[J].The finance , 2015(23):33-34.( In Chinese) 